\title{
LIFE STYLE MODIFICATION AMONG DIABETIC PATIENTS
}

\author{
NABI G ${ }^{1}$, KALAM KA ${ }^{2}$, RAHMAN NMW ${ }^{3}$, RABBANI $\mathrm{R}^{4}$, CHOWDHURY TI ${ }^{5}$

\begin{abstract}
:
Lifestyle modifications have key role in the management of diabetes. Awareness about the changes in lifestyle can play a vital role in the management of diabetes. There is a need of health education programs for diabetics and general population. As the diabetes is a slow progressive disease which causes target organ damage if not control. Study shows that controlled diabetics has also risk of target organ damage. Managing a diabetic patient needs to be combination of diet, discipline and drugs. Only drugs is given by the physician but the other two control parameter like diet and discipline is done by the patient himself. Life style modification can bring this two factor under control. Here we have studied 100 diabetic patient with following results.
\end{abstract}

Key words: Diabetes, Life style, awareness, compliance.

J Dhaka Med Coll. 2016; 25(1) : 46-52

\section{Introduction:}

Diabetes mellitus is a chronic and debilitating disease, is associated with a range of shortterm and long-term complications ${ }^{1}$. The management of diabetes mellitus and the management and prevention of the complications are important challenges of the present time. Studies indicate that genetic factors do not account entirely for the development of diabetes, and several environmental triggers have been implicated 2. The most important environmental risk factors for diabetes are obesity and physical inactivity. The massive explosion in obesity rates worldwide has largely been responsible for the increase in diabetes, and it is estimated that up to $80 \%$ of all new cases of diabetes can be attributed to obesity ${ }^{3}$. Change in life style has increased the incidence of obesity ${ }^{4}$. Despite several advances in the field of diabetology, it is unfortunate that there exists a low awareness of the disease among public ${ }^{5}$. For an effective control and prevention of diabetes; $87 \%$ of Bangladeshis, $88 \%$ of Pakistanis and $71 \%$ of Indians did not meet the guidelines as compared to $52 \%$ Europeans $^{6}$.
In Bangladesh prevalence of Diabetes Mellitus is $6.1 \%$. At present Bangladesh is in $10^{\text {th }}$ position but very shortly will be in $8^{\text {th }}$ position according to the total cases of diabetes in adult population (20 to 79 years) in $2030 .{ }^{7}$ The rapid rise of diabetes mellitus is one of the major health challenges. In fact, up to $80 \%$ of type- 2 diabetes is preventable by adopting a healthy diet, increasing physical activity and promoting a healthy lifestyle ${ }^{8,9}$. The important issues of lifestyle of a diabetic include their dietary habit, physical activity and exercise, regular monitoring blood glucose, physical care such as foot care, regular follow up etc. ${ }^{7}$

Therefore to manage diabetes, the individuals must have ample knowledge of their disease, medication, diet as well as risk factors. Thus health education is integral part in the management of diabetes. The present study was designed to assess the awareness about the role of lifestyle changes among the diabetic patients. There is a need of health education programs for diabetics and general public. This study will help to take more effective initiative to educate and empower diabetic patient about their disease and its fatal outcome if not manage early and consistently.

1. Dr. Golam Nabi, Assistant Prof.Medicine, Dept.of Medicine, Z.H.Sikder Womens Medical College \& Hospital.

2. Prof. Khan Abul Kalam Azad. Prof. of Medicine, dept.of medicine DMCH.

3. Dr. N.M.Wahidur Rahman, Assoc.Prof.department of Microbiology,ZHSWMC.

4. D. Dr. Rukshana Rabbani, Asst.Prof.dept of Radiotherapy, DMCH.

5. Dr. Thresika Islam Chowdhury. Asst.Prof. dept of Gyne \& Obs, ZHSWMC.

Correspondence: Dr. Golam Nabi, Assistant Prof.Medicine, Dept.of Medicine, Z.H.Sikder Womens Medical College \& Hospital. E-mail: lotus_pharma75@yahoo.com, Mob. 01819229570

Received: 11 February 2016

Accepted: 20 March 2016 


\section{Aim and objectives}

To observe the effect of lifestyle changes in the management of diabetes, among diabetic patients.

Study design: Cross sectional study.

Study place: Department of medicine $\mathrm{ZH}$ Sikder Women's Medical College \& Hospital

Number of case study: 100 (one hundred).

Study procedure: Patients who were clinically and laboratory findings suggestive of diabetes mellitus. Ages $>18$ and both sexes were included in the study and patients who were age $<18$ and unconscious or drowsy they were excluded in this study. All collected questionnaire were checked very carefully to identify the error in the data. Data processing work was consisting of registration schedules, editing computerization, preparation of dummy table, analyzing and matching of data. Information was collected who give consent and participated in the study willingly. After collection, data editing and clearing will be done manually and prepared for data entry and analysis by using computer software SPSS-19.

\section{Results:}

Table shows age group distribution of the study population, majority of them, $33 \%$ were $41-50$ year age group, followed by $26 \%$ were $51-60$ years age group, $24 \%$ were $>60$ years of age group. $13 \%$ were $31-40$ years age , 04\% were up to 20 years age group. Mean $( \pm \mathrm{SD})$ age was $51.74( \pm 13.02)$. Sex distribution of the study population shows male were $51 \%$ and $49 \%$ were female. Table shows occupational status, majority of them $40 \%$ were housewife, 25\% were retired service holder, $23 \%$ were service holder, $08 \%$ were business men. Table shows educational status of the study population, out of 100 respondent 38\% were secondary, $27 \%$ were primary, $19 \%$ were illiterate and $16 \%$ were in higher secondary and above. Figure shows $30 \%$ respondent were smoker and $70 \%$ were non smoker. Figure shows knowledge regarding signs \& symptoms of diabetes mellitus; majority of the respondent, $58 \%$ had poor knowledge, 23\% had good knowledge and
$19 \%$ had no idea. Regarding complications majority of the respondent, $57 \%$ had poor knowledge, 14\% had good knowledge and 29\% had no idea. Table shows most of the respondents, 91\% were taking treatment regularly, rest of them 09\% were irregular. Table shows majority of the respondent, 96\% had idea of diet chart, rest of them $04 \%$ had no idea. Table shows $75 \%$ of the respondents were following diet chart and 25\% were not following diet chart. Figure shows $50 \%$ of the respondent doing exercise occasionally, 34\% was $2-4$ time per week, and $16 \%$ were daily. Table shows majority of respondent $86 \%$ were avoid smoking and $14 \%$ were not avoid smoking. Table show majority of the respondent, $62 \%$ had no idea about the target Blood pressure, followed by $29 \%$ had reached their target of blood pressure, 09\% had not reached. Table shows investigation findings of the study population, Mean $\mathrm{Hb} \mathrm{A} 1 \mathrm{c}$ (\%) were $9.84( \pm 1.64)$, Serum Creatinine were $1.52( \pm 1.19)$, total cholesterol 215.12( \pm 42.68$)$ (mg/dL), LDL (mg/dL) 129.27 ( \pm 33.35$)$, Triglyceride $(\mathrm{mg} / \mathrm{dL}) 256.41( \pm 73.65)$ and mean HDL(mg/dL) 34.89( \pm 4.90$)$

\section{Table-I}

Age group distribution of the study population

\begin{tabular}{lcc}
\hline Age group & Frequency & Percent \\
\hline up to 20 years & 04 & 04.0 \\
31-40 years & 13 & 13.0 \\
41-50 year & 33 & 33.0 \\
51-60 years & 26 & 26.0 \\
>60 years & 24 & 24.0 \\
\hline Total & 100 & 100.0 \\
Mean $( \pm S D)$ & $51.74( \pm 13.02)$ & Range $18.0-80.0$ \\
\hline
\end{tabular}

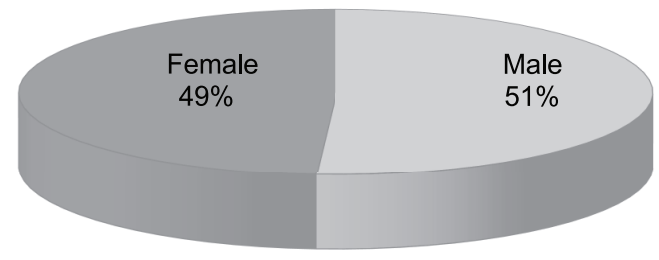

Fig.-1: Sex distribution of the study population 
Table-II

Occupational status of the study population

\begin{tabular}{lcc}
\hline $\begin{array}{l}\text { Occupation } \\
\text { Percent }\end{array}$ & Occupation & Frequency \\
\hline Service & 23 & 23.0 \\
Business & 08 & 08.0 \\
House wife & 40 & 40.0 \\
Retired & 25 & 25.0 \\
Others & 04 & 04.0 \\
\hline Total & 100 & 100.0 \\
\hline
\end{tabular}

Table shows occupational status, majority of them $40 \%$ were house wife, $25 \%$ were retired service holder, $23 \%$ were service holder, $08 \%$ were business men.

Figure shows 30\% respondent were smoker and $70 \%$ were non smoker.

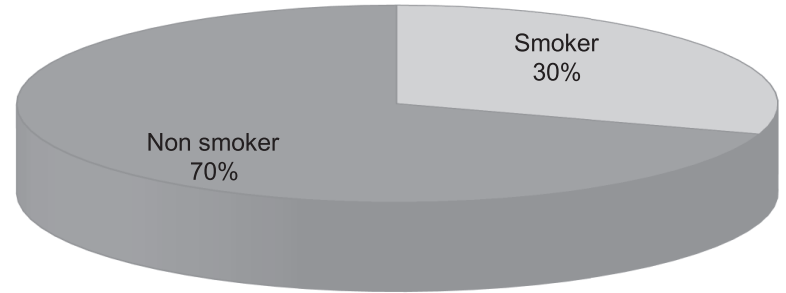

Fig.-2: Smoking habit of the study population

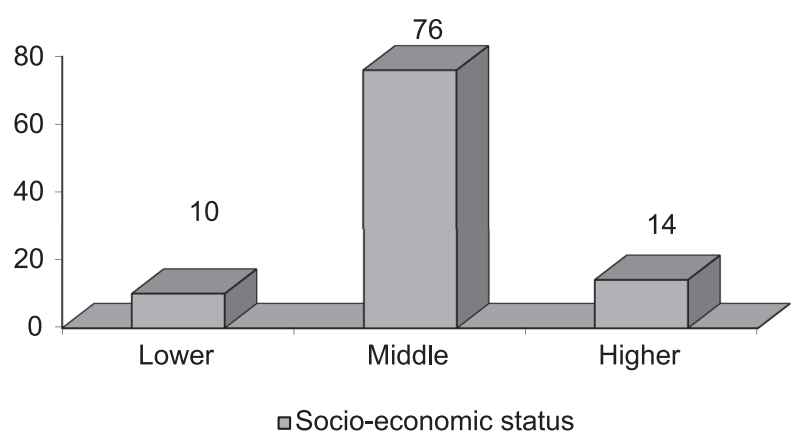

Fig.-3: Socio-economic status of the study population

Table-III

Educational status of study population

\begin{tabular}{lcc}
\hline Educational Status & Number & Percentage \\
\hline Illiterate & 19 & 19 \\
Primary & 27 & 27 \\
Secondary & 38 & 38 \\
Higher secondary and above & 16 & 16 \\
\hline
\end{tabular}

Table shows educational status of the study population, out of 100 respondent 38\% were secondary,27\% were primary, $19 \%$ were illiterate and $16 \%$ were in higher secondary and above.

Figure shows knowledge regarding signs \& symptoms of diabetes mellitus; majority of the respondent, $58 \%$ had poor knowledge, $23 \%$ had good knowledge and 19\% had no idea. Regarding complications majority of the respondent, 57\% had poor knowledge, 14\% had good knowledge and $29 \%$ had no idea.

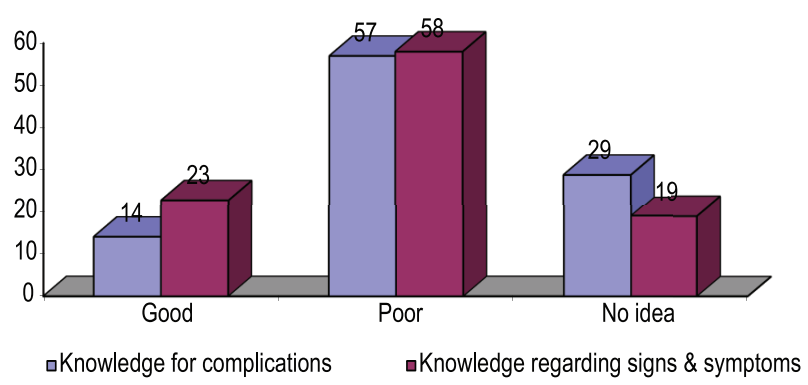

Fig.-4: Knowledge regarding signs, symptoms and complications of diabetes

Table-IV

Treatment status of the respondent

\begin{tabular}{lcc}
\hline Taking treatment & Frequency & Percent \\
\hline Regular & 91 & 91.0 \\
Irregular & 09 & 09.0 \\
Total & 100 & 100.0 \\
\hline
\end{tabular}

Table shows most of the respondents, 91\% were taking treatment regularly, rest of them 09\% were irregular.

Table-V

Idea of diet chart

\begin{tabular}{lcc}
\hline & Frequency & Percent \\
\hline Idea of diet chart & 96 & 96.0 \\
No Idea of diet chart & 04 & 04.0 \\
\hline Total & 100 & 100.0 \\
\hline
\end{tabular}

Table shows majority of the respondent, 96\% had idea of diet chart, rest of them $04 \%$ had no idea. 
Table-VI

Follow diet chart of the study population

\begin{tabular}{lcc}
\hline Follow diet chart & Frequency & Percent \\
\hline Follow diet chart & 75 & 75.0 \\
Not follow diet chart & 25 & 25.0 \\
Total & 100 & 100.0 \\
\hline
\end{tabular}

Table shows $75 \%$ of the respondents were following diet chart and 25\% were not following diet chart.

Figure shows $50 \%$ of the respondent doing exercise occasionally, 34\% were 2-4 time per week, and $16 \%$ were daily.

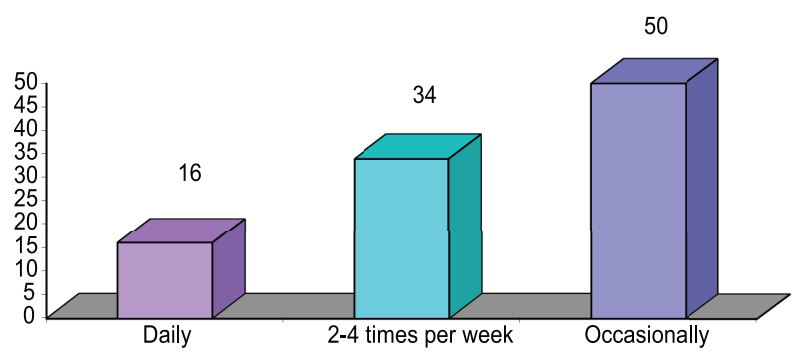

Fig.-5 : Exercise status of the respondent

Table-VII

Respondent avoid smoking

\begin{tabular}{lcc}
\hline Avoid smoking & Frequency & Percent \\
\hline Avoid smoking & 86 & 86.0 \\
Not avoid smoking & 14 & 14.0 \\
Total & 100 & 100.0 \\
\hline
\end{tabular}

Table shows majority of respondent $86 \%$ were avoid smoking and $14 \%$ were not avoid smoking.

Table-VIII

Reaching target blood pressure

\begin{tabular}{lcc}
\hline & Frequency & Percent \\
\hline Reaching target of BP & 29 & 29.0 \\
Not reaching target of BP & 09 & 09.0 \\
No idea about target of BP & 62 & 62.0 \\
\hline Total & 100 & 100.0 \\
\hline
\end{tabular}

Table show majority of the respondent, $62 \%$ had no idea about the target Blood pressure, followed by $29 \%$ had reached their target of blood pressure, 09\% had not reached.

Figure shows out of 100 cases 54\% were normal weight, 33\% were over weight and 13\% were obese.

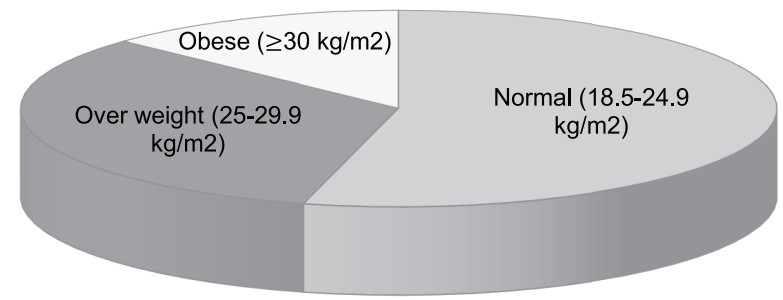

Fig.-6 : BMI of the study population

Table-IX

Respondent taking care of foot

\begin{tabular}{lcc}
\hline Care of foot & Frequency & Percent \\
\hline Taking care of foot & 70 & 70.0 \\
Not taking care of foot & 30 & 30.0 \\
Total & 100 & 100.0 \\
\hline
\end{tabular}

Table shows $70 \%$ respondent were taking care of foot and 30\% were not taking care of foot.

Table-X

Investigation findings

\begin{tabular}{lcc}
\hline Investigation & Mean $( \pm \mathrm{SD})$ & $\begin{array}{c}\text { Range } \\
\text { Minimum-maximum }\end{array}$ \\
\hline HbA1C & $9.84( \pm 1.64)$ & $6.50-13.20$ \\
Serum & $1.52( \pm 1.19)$ & $0.69-7.0$ \\
Creatinine & & \\
Total & $215.12( \pm 42.68)$ & $121.0-312$ \\
cholesterol & & \\
LDL & $129.27( \pm 33.35)$ & $49.0-214$ \\
HDL & $34.89( \pm 4.90)$ & $19-49$ \\
TG & $256.41( \pm 73.65)$ & $115.0-378.0$ \\
\hline
\end{tabular}

Table shows investigation findings of the study population, Mean Hb A1c (\%) were 9.84 ( \pm 1.64$)$, Serum Creatinine were 1.52( \pm 1.19$)$, total cholesterol 215.12 $( \pm 42.68)(\mathrm{mg} / \mathrm{dL}), \mathrm{LDL}(\mathrm{mg} / \mathrm{dL})$ $129.27 \quad( \pm 33.35), \quad$ Triglyceride $(\mathrm{mg} / \mathrm{dL})$ $256.41( \pm 73.65)$ and mean $\mathrm{HDL}(\mathrm{mg} / \mathrm{dL})$ $34.89( \pm 4.90)$ 


\section{Discussion}

American Diabetic Association has defined self- management education as the process of providing the person with diabetes the knowledge and skill that is needed to perform self -care, manage crises and make life style changes. To achieve such standerd self- care patients and doctor should work together. ${ }^{10}$ There is emphasis on teaching pathophysiology and its relation with treatment, nutritional aspects, medications, complications, goal setting and psychosocial adjustments. Considering these standards, we formulated our questionnaire.

In this study majority of the respondent, 33\% were 41-50 year age group; followed by $26 \%$ were 51-60 years age group, 24\% were > 60 years of age group. $13 \%$ were $31-40$ years age , $04 \%$ were up to 20 years age group. Mean $( \pm$ SD) age were $51.74( \pm 13.02)$.

Carolino et al. ${ }^{11}$ study reported, there was only one patient older than 80 years, while the age range with the highest concentration of individuals was from 60 to 69 years old (51.51\%), followed by 50 to 59 years (30.30\%) and 70 to 79 years $(16.67 \%)$. These findings are coherent with those found in other studies carried out with samples originating from health services. ${ }^{15}$ Such evidence can be justified by the fact that a higher frequency of DM2 occurs at approximately 60 years of age. That is similar to in this study.

The another study Rahman et al. ${ }^{12}$ Reported the mean age of the respondents was 54.96 years and $60 \%$ of them were in the 45 to 64 years age group and age distribution was comparable with that of type 2 diabetes in developing countries. ${ }^{13}$

In this series majority of the respondent, $40 \%$ were house wife, $25 \%$ were retired service holder, 23\% were service holder, 08\% were business men.

Rahman et al. ${ }^{12}$ study, found Service holder 21.5\%, Housewife $41.2 \%$,Retired 23.2\% and Businessman $14.1 \%$ that is similar to our study.

This study shown majority of respondent, $76 \%$ came from middle class socio-economic background while 14\% from higher and 10\% came from lower class. Regarding the educational status of the study population, out of 100 respondent $38 \%$ was secondary, $27 \%$ were primary, $19 \%$ were illiterate and $16 \%$ were in higher secondary and above. Majority of the respondent, $58 \%$ had poor knowledge of signs and symptoms of DM while $23 \%$ had good knowledge and 19\% had no idea. Regarding complications of diabetes mellitus; majority of the respondent, $57 \%$ had poor knowledge, $14 \%$ had good knowledge while $29 \%$ had no idea. Both affordability and literacy may be the problem in diabetes education and management. Education of vulnerable communities can become a costeffective public health strategy. It has been shown that self-care among individuals with type 2 diabetes improved glycemic control ${ }^{14}$ and reduced complications. ${ }^{15}$

Maina et al. ${ }^{16}$ study reported , 358 (18\%) of the respondents had tertiary education, 737 $(37.2 \%)$ had secondary education, 725 (36.6\%) had primary education while $162(8.2 \%)$ had no education at all. $575(29 \%)$ of respondents had good knowledge of signs and symptoms of diabetes while $1407(71 \%)$ of respondents had poor knowledge on what diabetes is. 518 $(26.1 \%)$ could correctly identify the probable causes of diabetes mellitus while $1464(73.9 \%)$ could not. Only $523(26.4 \%)$ of the respondents could identify complications of diabetes they knew while $1459(73.4 \%)$ had very little or no knowledge of complications of diabetes.

The findings of this study reveal a serious deficiency in knowledge of diabetes among community members in Kenya. Only $27.2 \%$ of the people interviewed had good knowledge of diabetes. Puepet et al. ${ }^{17}$ found a similar level of knowledge of diabetes, $30.2 \%$, among patients with diabetes in Jos State, Nigeria ${ }^{17}$. Dinesh et al. ${ }^{18}$ in a study in western Nepal, noted a lack of awareness of diabetes even in patients who had had the disease for a long time 18. Even in a developed country set up, Baradaran and Jones also found that knowledge about diabetes amongst ethnic groups in Glasgow was very low ${ }^{19}$.

In this study $91 \%$ respondents were taking treatment regularly, rest of them 09\% were 
irregular. 96\% had idea of diet chart, rest of them, $04 \%$ had no idea. $75 \%$ of the respondents were following diet chart while $25 \%$ were not following diet chart. Compared with study of Ulvi et al. ${ }^{20}$ reported $14.7 \%$ respondent followed regular diet regimen, $85.3 \%$ were not followed regular diet regimen. $22.7 \%$ had regular checkup and $77.33 \%$ had no regular checkup.

In this series $30 \%$ respondent were smoker and $70 \%$ were non-smoker. Only $35 \%$ of the respondents were doing exercise regularly while $40 \%$ were occasional and $25 \%$ were doing no exercise. On the basis BMI 54\% were normal weight while $33 \%$ were over-weight and $13 \%$ were obese. Only $29 \%$ of respondents had reached their target of blood pressure while majority of them, $62 \%$ had no idea of target blood pressure and $09 \%$ had not reached. It indicates poor level of awareness regarding the importance of exercise and weight control among diabetic patient getting treatment at tertiary center.

Awareness about Diabetes Mellitus was found to be similarly low in a community based study in Malaysia. ${ }^{21}$ This study and similar other studies have shown undisputable evidence that regarding poor awareness level of diabetes. There were no studies found which could contradict the results of this study nor show more positive results when it comes to public awareness. The prevalence of diabetes has increased drastically in Oman over the last decade, while knowledge of diabetes was suboptimal. ${ }^{21}$ Attendees of a primary care center in eastern Saudi Arabia were found to have poor knowledge on DM risk factors and preventative measures. ${ }^{22}$ Education and age were found to be the most important predictors of knowledge. ${ }^{22}$

In another study Malathy et al. ${ }^{23}$ observed that $54(39.42 \%)$ of the test population were overweight and $31(22.6 \%)$ of them were obese, which indicates the poor level of awareness regarding the benefits of physical activity and exercises in reducing the BMI. Among the males $17(12.4 \%)$ were smokers. In the test group, 21 (15.3\%) patients had systolic BP e" $140 \mathrm{~mm} \mathrm{Hg}$ and $36(26.3 \%)$ had diastolic BP e" $90 \mathrm{~mm} \mathrm{Hg}$. That nearly support this study.
In this series $70 \%$ respondent were taking care of foot while $30 \%$ were not taking care of foot. This implies poor awareness of complications regarding diabetic foot. Compared with Malathy et al. ${ }^{23}$ study reported 46 (33\%) of patients knew about the importance of foot care.

Investigation findings of the study population, Mean HbA1c (\%) were 9.84 ( \pm 1.64$)$, Serum Creatinine were $1.52( \pm 1.19)$, total cholesterol 215.12( \pm 42.68$)(\mathrm{mg} / \mathrm{dL}), \mathrm{LDL}(\mathrm{mg} / \mathrm{dL}) 129.27$ ( \pm 33.35$)$, Triglyceride $(\mathrm{mg} / \mathrm{dL}) 256.41( \pm 73.65)$ and mean $\mathrm{HDL}(\mathrm{mg} / \mathrm{dL}) 34.89( \pm 4.90)$. These implies poor glycemic control with high TG and low HDL of the majority of the patient.

Carolino et al. ${ }^{11}$ study reported, Total cholesterol (mg/dl) $213.78 \pm 37.16$, LDLcholesterol (mg/dl) $133.66 \pm 31.44$, HDLcholesterol (mg/dl) $43.48 \pm 14.54$, Triglycerides (mg/dl) 174.20 \pm 87.41 , Fasting glycaemia (mg/ dl) $117.87 \pm 33.20$ this result is nearly similar to our study.

\section{Conclusion}

Knowledge about diabetes mellitus is a prerequisite for individuals and communities to take action to control the disease. However, research to assess knowledge deficiencies and their relation to health-seeking behavior is lacking in most developing countries. Diabetes education, with consequent improvements in knowledge, attitudes and skills, will lead to better control of the disease, and is widely accepted to be an integral part of comprehensive diabetes care.

\section{References}

1. Hoff AL, Wagner JL, Mullins LL, and Chaney JM. Behavioral management of type 2 diabetes. Cohen LM, McChargue DE and Collins FL (Eds.). The health psychology handbook-. Practical issues for the behavioral medicine specialist 2003; pp. 303324. Thousand Oaks, CA: Sage Publications.

2. Akerblorn HK, Vaarala O, Hyoty H, et al. Environmental factors in the etiology of type 1 diabetes. American Journal of Medical Genetics 2002; 115:18-29.

3. Lean TA and Richard 1G. Diagnosis, epidemiology and pathogenesis of diabetes mellitus: an update for psychiatrists. Available at http:// bjp.rcpsych.org/cgi/ content/full/1 84/47/s 55\#REF36 \#REF36. 
4, Nanan DJ. The obesity pandemic-implications for Pakistan. J Pak Med Assoc. 2002; 52:342-6.

5. Gary TL, Genkinger JM, Guallar E, Peyrot M and Brancati FL. Meta-analysis of randomized educational and behavioral interventions in type 2 diabetes. Diabetes Educ 2003; 29:488-501.

6. Hayes L, White M, Unwin N, et al. Patterns of physical activity and relationship with risk markers for cardiovascular disease and diabetes in Indian, Pakistani, Bangladeshi and European adults in a UK Professiona population. J Public Health Med 2002; 24(3):170-8.

7. Bangladesh Diabetic Samity (BADAS)

8. Nelson KM, Reiber G, Boyko EJ. Diet and exercise among adults with type 2 diabetes: findings from the Third National Health and Nutrition Examination Survey (NHANES III). Diabetes Care 2002;25: 1722-1728.

9. American Diabetes Association. The prevention or delay of type 2 diabetes. Diabetes Care 2002; 25:742 - 749 .

10. Shah VN, Kamdar PK, and Shah N .Assessing the knowledge, attitudes and practice of type 2 diabetes among patients of Saurashtra region, Gujarat ,J Diabetes Dev Ctries. 2009

11. Carolino IDR, Molena-Fernandes CA, Tasca RS, Marcon SS, Cuman RKN, Risk factors in patients with type 2 diabetes mellitus, Rev Latino-am Enfermagem 2008; 16(2):238-44.

12. Rahman M, Rahman MA, Flora MS, RakibuzZaman M . Depression and associated factors in diabetic patients attending an urban hospital of Bangladesh, International Journal of Collaborative Research on Internal Medicine \& Public Health Vol. 3 5o. 1 (2011), 64-76

13. Wild S, Roglic G, Green A, Sicree R, King H. Global Prevalence of Diabetes: Estimates for the year 2000 and projections for 2030. Diabetes Care 2004;27:1047-53.

14. Ramachandran A, Snehalatha C, Mary S, Mukesh $B$, Bhaskar AD, Vijay V. Indian Diabetes Prevention Programme (IDPP): The Indian Diabetes Prevention Programme shows that lifestyle modification and metformin prevent type 2 diabetes in Asian Indian subjects with impaired glucose tolerance (IDPP-1) Diabetologia. 2006;49:289-97. [PubMed]

15. Heisler M, Pietee JD, Spencer M, Kieffer E, Vijan $\mathrm{S}$. The relationship between knowledge of recent $\mathrm{HbA} 1 \mathrm{c}$ values and diabetes care understanding and self-management. Diabetes Care. 2005;28:816-22. [PubMed]

16. Maina WK, Ndegwa ZM, Njenga EW, Muchemi EW. Knowledge, attitude and practices related to diabetes among community members in four provinces in Kenya The Pan African Medical Journal. 0210;7:2

17. Puepet FH, Mijinyawa BB, Akogu I, Azara I. Knowledge, attitude and practice of patients with Diabetes Mellitus before and after educational intervention in Jos, Nigeria. The Journal of Medicine in the Tropics. 2007; 9(1): 3-10

18. Dinesh K Upadhyay, Subish Palaian, P Ravi Shankar, Pranaya Mishra. Knowledge, attitude and practice about Diabetes among Diabetes patients in Western Nepal. Rawal Medical Journal. 2008; 33 (1): $8-11$

19. Baradaran Hamid, Knill-Jones Robin. Assessing the knowledge, attitudes and understanding of type 2 diabetes amongst ethnic groups in Glasgow, Scotland. Practical Diabetes Int. 2004; 21(4): 143148

20. Ulvi OS, Chaudhary RY, Ali T, Khan MFA, Khan MK, Malik FA, et al.Investigating the awareness level about Diabetes Mellitus and associated factors in Tarlai (Rural Islamabad JPMA, 2009; 59:798; 2009

21. Yun LS, Hassan Y, Aziz NA, Aaisu A, Ghazali R. A comparison of knowledge of diabetes mellitus between patients with diabetes and healthy adults: a survey from north Malaysia. Patient Educ Couns 2007; 69: 47-54.

22. Aljoudi AS, Taha AZ. Knowledge of diabetes risk factors and preventive measures among attendees of a primary care center in eastern Saudi Arabia, Ann Saudi Med 2009; 29: 15-9.

23. Malathy R, Narmadha MP, Ramesh S, Alvin J M, and Dinesh B N, Effect of a diabetes counseling programme on knowledge, attitude and practice among diabetic patients in Erode district of South India. J Young Pharm. 2011; 3(1): 65-72. 